\title{
Locomotor Effects of a D1R Agonist Are DARPP-32 Dependent in Adult but not Weanling Mice
}

\author{
LENA SCOTT, HANS FORSSBERG, ANITA APERIA, AND ROCHELLYS DIAZ-HEIJTZ \\ Department of Woman and Child Health, Karolinska Institutet, Astrid Lindgren Children's Hospital \\ Q2:09, S-171 76 Stockholm, Sweden
}

\begin{abstract}
ABST
Evidence suggests that dopamine regulation of motor activity
undergoes postnatal maturation. To examine the role of the
dopamine 1 receptor (D1R)/dopamine- and cAMP-regulated
phosphoprotein of $32 \mathrm{kDa}$ (DARPP-32) signaling pathway for
this maturation, we studied the effects of a D1R agonist on motor
activity in weanling and adult wild-type (WT) mice and mice that
lack DARPP-32, a key messenger in the D1R signaling pathway.
Locomotor activity was not affected by D1R activation in WT
weanling mice but was significantly stimulated in WT adult
mice. This stimulation was absent in DARPP-32 (-/-) adult
mice. In contrast, the inhibitory effects that were observed on
rearing activity in WT weanling and adult mice were present in
\end{abstract}
DARPP-32 (-/-) mice. DARPP-32 plays a key role for development of D1R motor stimulatory effects. (Pediatr Res 58: 779-783, 2005)

\[ \text { Abbreviations } \]
ADHD, attention-deficit/hyperactivity disorder
DARPP-32, dopamine- and cAMP-regulated phosphoprotein
of $32 \mathrm{kDa}$
D1R, dopamine 1 receptor
PP-1, protein phosphatase-1
WT, wild type

Dopamine plays a central role in the control of motor activity and cognitive functions. Alterations in the dopamine system have been linked to a number of disorders, including attention-deficit/hyperactivity disorder (ADHD), the most common neuropsychiatric disorder in children and young teenagers (1). Numerous studies in children with ADHD have demonstrated that potentiating of the action of dopamine via psychostimulants has a positive effect on hyperactivity (2).

The downstream effects of dopamine are mediated via a complex interaction between the two subtypes of dopamine receptors, D1- and D2-like receptors (3). Dopamine- and cAMP-regulated phosphoprotein of $32 \mathrm{kDa}$ (DARPP-32) plays an important role in mediating the actions of dopamine and other neurotransmitters that act on dopaminoceptive neurons. DARPP-32 is phosphorylated by activation of D1 receptors (D1R) via the cAMP pathway. DARPP-32 in its activated state is a potent inhibitor of protein phosphatase-1 (PP-1) (4). Several signaling pathways converge on DARPP-32, making it a main modulator of many downstream effects of D1R activation

Received July 30, 2004; accepted January 28, 2005.

Correspondence: Lena Scott, Ph.D., Department of Woman and Child Health, Karolinska Institutet, Astrid Lindgren Children's Hospital Q2:09, S-171 76 Stockholm, Sweden; e-mail: scott@acc.umu.se.

The Märta and Gunnar Philipson foundation (A.A.), Vetenskaps Rådet (A.A.) and the National Network for Neuroscience (L.S.), and the Sven Jerring and Harald Jeansson Foundations (R.D.-H.) supported this work.

DOI: 10.1203/01.PDR.0000180553.23507.31
(5). Studies using DARPP-32-deficient mice have indicated that DARPP-32 is involved in mediating effects of many psychostimulant and antipsychotic drugs (6). Recent work in rats from our laboratory has shown that D1R activation can have both inhibitory and stimulatory effects on motor activity (7). However, little is known about the signaling pathways that mediate these effects.

Here we have investigated whether D1R-mediated motor inhibitory and stimulatory effects are dependent on the DARPP-32 signaling pathway, as well as on postnatal maturational changes. For this purpose, we investigated the motor responses to the full and selective D1-like receptor agonist (8) SKF-81297 in nonhabituated weanling and adult wild-type $(+/+)($ WT) and DARPP-32 (-/-) mice. The use of a model in which the animals had a high baseline activity (nonhabituated) made it possible to examine not only stimulatory but also inhibitory motor response to D1R activation.

\section{METHODS}

Subjects. Weanling (3 wk old) and adult (12-15 wk old) male WT $(+/+)$ and DARPP-32 (-l-) male mice were used. The animals were obtained from the Rockefeller University and were generated from C57BL/6 mice as previously described (6). The WT and DARPP-32 (-I-) mice used in this study were generated from the offspring of DARPP- $32^{+/+} \times$DARPP- $32^{+/+}$and DARPP- $32^{-1-} \times$ DARPP- $32^{-1-}$ mating pairs. The animals were weaned after $21 \mathrm{~d}$ and housed in groups of eight under controlled conditions of light:dark cycle $(12: 12 \mathrm{~h}$, lights on at $0800 \mathrm{~h})$. Food and tap water were available ad libitum. The experiments were approved by the local Committee on the Ethics of Animal Experimentation, Stockholm, Sweden. All experimen- 
tal procedures complied with internationally approved standards for animal welfare. There was no size or weight difference between the WT and DARPP-32 (-I-) mice in either age group. The weight for weanling WT and DARPP-32 $(-/-)$ was $6.51 \pm 0.25$ and $7.15 \pm 0.36 \mathrm{~g}(p=0.155)$, respectively. For adult WT and DARPP-32 (-/-), was the weight $28.17 \pm 0.70$ and $27.57 \pm 1.05 \mathrm{~g}(p=0.641)$, respectively.

Motor activity measurements and behavioral procedure. Motor activity (locomotion and rearing) was measured in a multibox ActiMot detection system (TSE, Bad Homburg, Germany) that contained two activity cages in which two mice were tested simultaneously as previously described (7). The light-barrier strip ( $z$ coordinate) for detecting rearing activity was adjusted according to the age/size of the animal. Testing took place between 1000 and $1700 \mathrm{~h}$ under dimmed light conditions. All experiments were carried out with nonhabituated mice. Mice were used only once to avoid carryover effects. After an i.p. injection of vehicle $(0.9 \% \mathrm{NaCl})$ or SKF-81297 [(+/-)-6-chloro7,8-dihydroxyl-1-phenyl-2,3,4,5-tetrahydro-1H-3-benzazepine hydrobromide; Research Biochemical and International, Natick, MA; $3 \mathrm{mg} / \mathrm{kg}$ ] calculated as salt weight, the animal was immediately placed in the center of an activity box. Data were collected at 5-min intervals over a period of $90 \mathrm{~min}$. The data were recorded as number of meters traveled and number of rears over a 5-min period for locomotor and rearing activity, respectively.

In situ hybridization. The sense and antisense riboprobes for D1R were prepared from a $1.373-\mathrm{kb}$ Bam $\mathrm{H} 1$ site fragment of the rat $\mathrm{D}_{1 \mathrm{~A}} \mathrm{cDNA}$ as described previously (9). The plasmid that contained the dopamine $D_{1 A}$ receptor was provided by Dr. Marc Caron (Duke University Medical Center, University of North Carolina, Durham, NC). The brains from weanling and adult WT and DARPP-32 (-/-) mice were rapidly dissected and frozen on dry ice and then stored at $-80^{\circ} \mathrm{C}$ until sectioned. The brains were cut into serial coronal sections $20 \mu \mathrm{m}$ thick and stored at $-80^{\circ} \mathrm{C}$ until used. Four animals were used in each group, and two sections from eight different levels were collected from each brain. The in situ hybridization was performed as previously described (10). After in situ hybridization, the dried sections were placed against a $\beta$-Max film and stored at room temperature. After $1-2 \mathrm{wk}$, the films were developed.

Statistical analysis. All behavioral experiments were analyzed using repeated measures ANOVA [treatment (dose), genotype, age, and time as main factors]. When ANOVA indicated a significant overall effect of treatment at $p$ $<0.05$ level; post hoc testing was performed using Fisher's least significant differences test (PLSD). Statistical analysis of mRNA expression was performed using the $t$ test. For all analyses, significance was assigned at the $p<$ 0.05 .

\section{RESULTS}

\section{Effects of SKF-81297 on Locomotor Activity in WT and DARPP-32 (-/-) Mice}

WT mice. The overall time courses of the effects of SKF81297 on locomotor activity of male weanling and adult WT mice are presented in Fig. $1 A$ and $B$, respectively. SKF-81297 $(3 \mathrm{mg} / \mathrm{kg}$ ) produced no significant effects on locomotor activity of weanling WT mice (Fig. 1A). In contrast, SKF-81297 (3 $\mathrm{mg} / \mathrm{kg})$ significantly $(p<0.05)$ stimulated locomotor activity in adult WT mice starting at $25 \mathrm{~min}$ and lasting up to $60 \mathrm{~min}$ after injection (Fig. 1B).

In a series of pilot studies, we also tested a $10 \mathrm{mg} / \mathrm{kg}$ dose of SKF-81297 and found in adult mice a similar response to that observed with the $3 \mathrm{mg} / \mathrm{kg}$ dose. Importantly, this higher dose of SKF-81297 was found to be highly toxic in weanling mice. The window for a physiologic effect in weanling mice was found to be very narrow for SKF-81297. After $10 \mathrm{mg} / \mathrm{kg}$, only $50 \%$ of the weanling mice survived the pilot tests.

DARPP-32 (-/-) mice. The overall time courses of the effects of SKF-81297 on locomotor activity of male weanling and adult DARPP-32 (-/-) mice are presented in Fig. $2 A$ and $B$, respectively. Similar to WT mice, SKF-81297 (3 mg/kg) had no significant effects on locomotor activity in weanling DARPP-32 (-/-) mice (Fig. 2A). In contrast to what was observed in WT adult mice, adult DARPP-32 (-/-) mice

\section{a) Weanling}

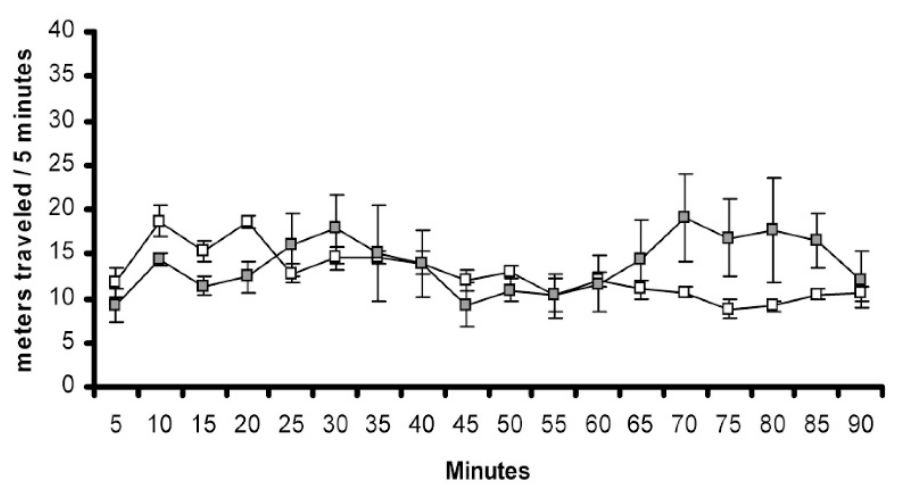

b) Adult

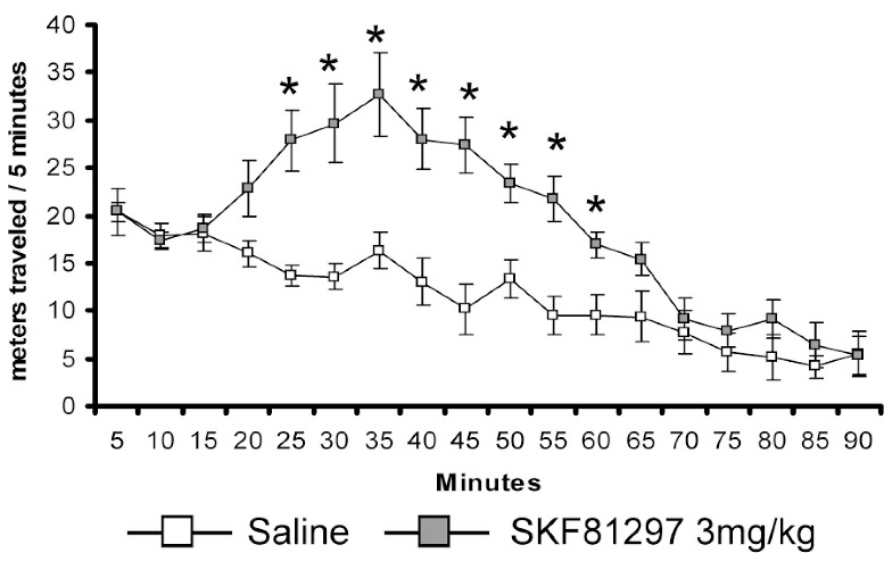

Figure 1. The time course of effects of SKF-81297 (3 mg/kg) on locomotor activity of male weanling $(A)$ and adult $(B)$ WT mice (means of meters traveled \pm SEM). Animals that received vehicle (weanling $n=5$, adult $n=6$ ) and SKF-81297 (weanling $n=5$, adult $n=5$ ) are indicated by $\square$ and $\square$, respectively. Significant differences from vehicle injected group of the same age are shown: $* p<0.05$, according to post hoc comparisons by Fisher's PLSD test.

exhibited no stimulatory response to SKF-81297 (Fig. 2B). In fact, the overall locomotor activity pattern was significantly different between adult WT and adult DARPP-32 (-/-) mice [time $\times$ dose $\times$ genotype interaction $F(17,289) F=3.050, p$ $<0.0001$, ANOVA analysis for adult mice]. No such interactions were found for weanling WT and DARPP-32 (-/-) mice.

\section{Effects of SKF-81297 on Rearing Activity in WT and DARPP-32 (-/-) Mice}

WT mice. The overall time courses of the effects of SKF81297 on rearing activity of male weanling and adult WT mice are presented in Fig. $3 A$ and $B$, respectively. SKF-81297 (3 $\mathrm{mg} / \mathrm{kg}$ ) produced a significant reduction on rearing activity in weanling WT mice throughout most of the testing period $(p<$ 0.05; Fig. 3A). However, in adult WT mice, SKF-81297 (3 $\mathrm{mg} / \mathrm{kg}$ ) produced on rearing activity a biphasic effect that was characterized by an initial short inhibition (i.e. during the 10to 20-min time interval; $p<0.05$, ANOVA for each time point) followed by a robust stimulation (i.e. during the 35- to 65-min time interval; $p<0.05$, ANOVA for each time point; Fig. 3B). 
a) Weanling

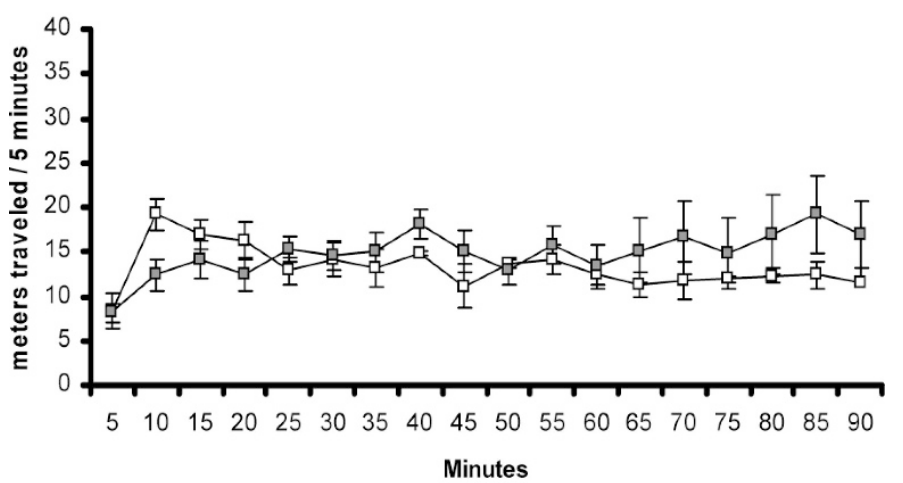

b) Adult

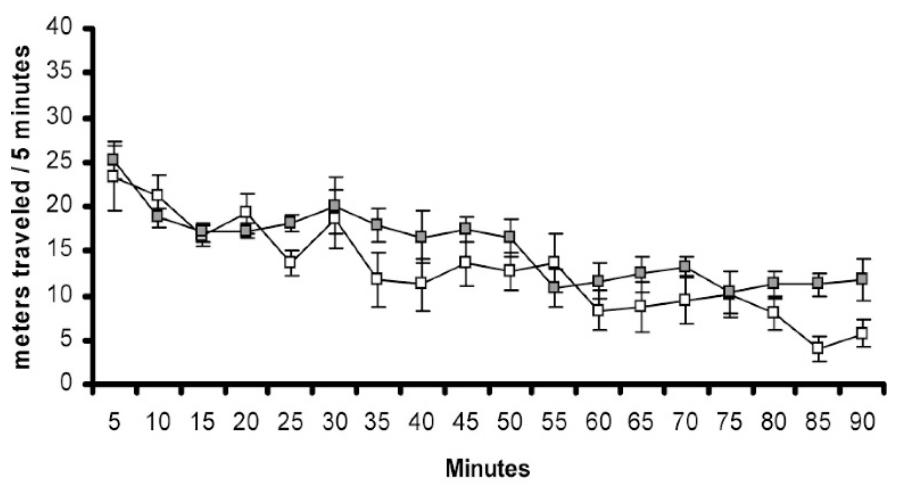

$-\square-$ Saline $-\square-$ SKF81297 3mg/kg

Figure 2. The time course of effects of SKF-81297 (3 mg/kg) on locomotor activity of male weanling $(A)$ and adult $(B)$ DARPP-32 (-/-) mice (means of meters traveled \pm SEM). Animals that received vehicle (weanling $n=5$, adult $n=5$ ) and SKF-81297 (weanling $n=8$, adult $n=5$ ) are indicated by $\square$ and $\square$, respectively. No significant differences, $p>0.05$.

DARPP-32 (-/-) mice. The overall time courses of the effects of SKF-81297 on rearing activity of male weanling and adult DARPP-32 (-/ $)$ mice are presented in Fig. $4 A$ and $B$, respectively. In DARPP-32 (-/-) weanling mice, SKF-81297 $(3 \mathrm{mg} / \mathrm{kg})$ produced a significant reduction on rearing activity throughout most of the testing period ( $p<0.05$; Fig. 4A). This effect was similar to what was observed in weanling WT mice (Fig. 3A). In adult DARPP-32 (-/-) mice, SKF-81297 produced a weak but significant $(p<0.05)$ initial inhibition (Fig. $4 B$ ). However, the subsequent stimulatory effect that was observed in WT adult mice (Fig. 3B) was absent in DARPP-32 $(-/-)$ mice (Fig. 4B). In fact, the overall rearing activity pattern was significantly different between adult WT and adult DARPP-32 $(-/-)$ mice [time $\times$ dose $\times$ genotype interaction $F(17,289) F=2.719, p=0.0003$, ANOVA analysis for adult mice). No such interactions were found for weanling mice.

\section{D1R mRNA Expression in WT and DARPP-32 (-/-) Mice}

To examine whether the lack of motor stimulation in response to the D1R agonist in DARPP-32 (-/-) mice was the result of a down-regulation of D1R expression, we performed an in situ hybridization study, using riboprobes for the D1R. a) Weanling

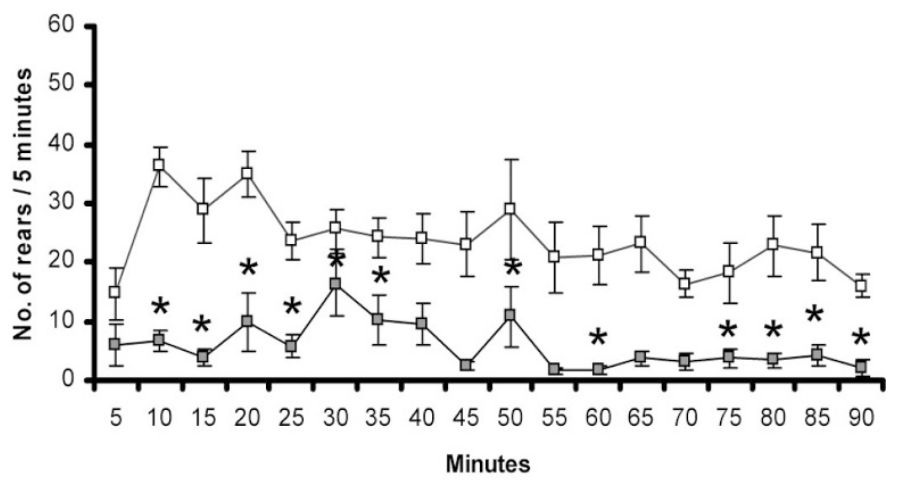

b) Adult
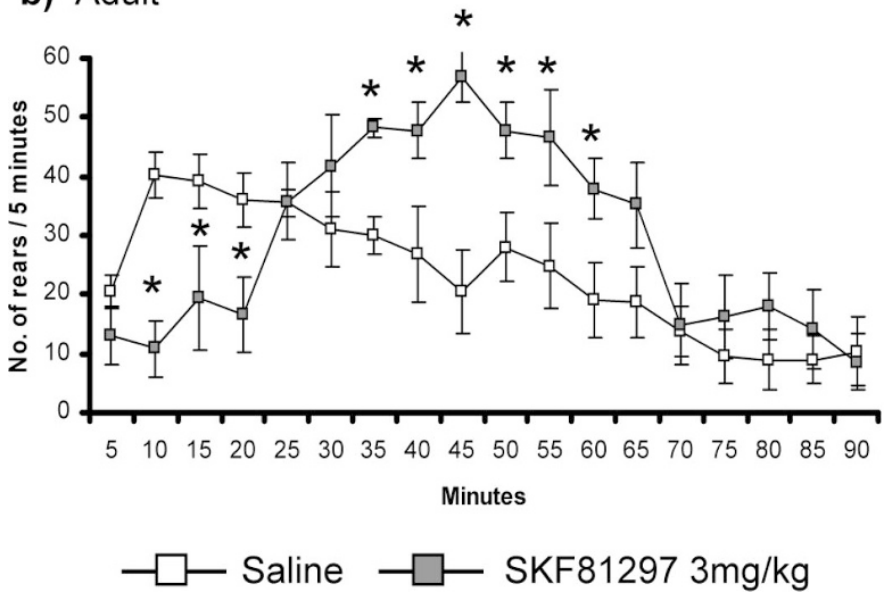

Figure 3. The time course of effects of SKF-81297 (3 mg/kg) on rearing activity of male weanling $(A)$ and adult $(B)$ WT mice (means of meters traveled \pm SEM). Animals that received vehicle (weanling $n=5$, adult $n=6$ ) and SKF-81297 (weanling $n=5$, adult $n=5$ ) are indicated by $\square$ and $\square$, respectively. Significant differences from vehicle-injected group of the same age are shown: $* p<0.05$, according to post hoc comparisons by Fisher's PLSD test.

Figure 5 shows D1R autoradiograms of all groups of mice studied. We found in WT adult mice a high D1R mRNA expression in caudate putamen, nucleus accumbens, and olfactory tuberculum and somewhat lower levels in the prefrontal cortex. We found no significant difference in the D1R mRNA expression in any of the above regions between the WT and DARPP-32 (-/-) mice in either of the age groups (Table 1). The specificity of the signals obtained by in situ hybridization was confirmed using the D1R sense riboprobes. There was no detectable signal when the sense riboprobe was used (data not shown). In addition, background levels of the films were very low.

\section{DISCUSSION}

The question of whether the sensitivity of the dopamine system continues to change during childhood and adolescence is of relevance for the understanding of symptoms and treatment of neurodevelopmental motor disorders such as ADHD. Here we have used a mouse model to address this question and could demonstrate that the motor stimulatory response to do- 


\section{a) Weanling}

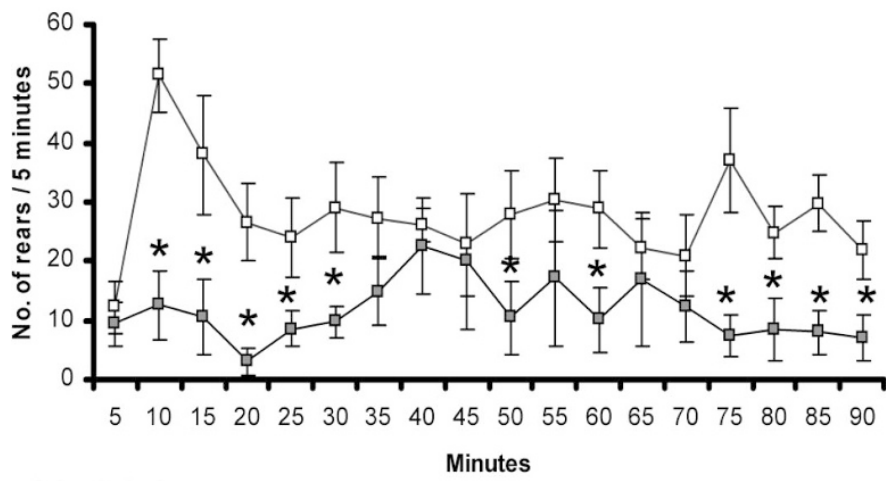

b) Adult

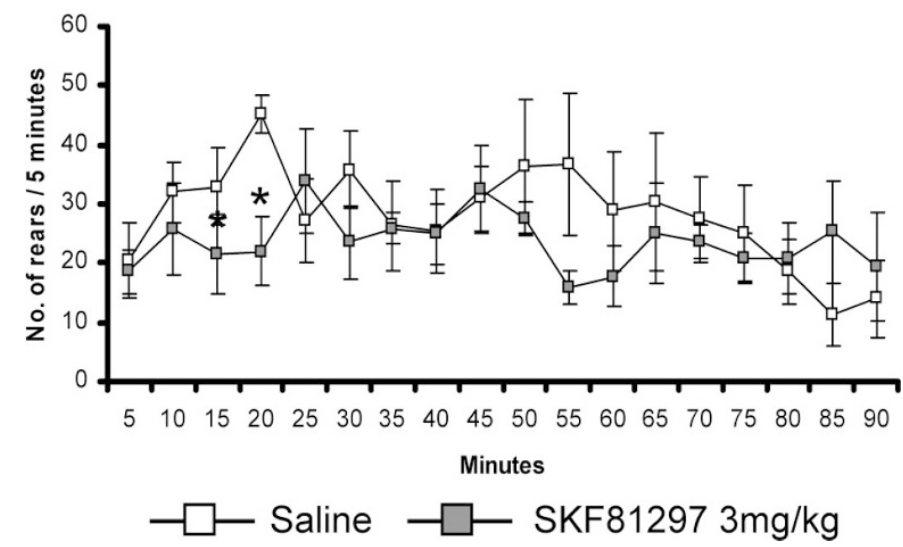

Figure 4. The time course of effects of SKF-81297 $(3 \mathrm{mg} / \mathrm{kg})$ on rearing activity of male weanling $(A)$ and adult $(B)$ DARPP-32 $(-/-)$ mice (means of meters traveled $\pm \mathrm{SEM}$ ). Animals that received vehicle (weanling $n=5$, adult $n=5$ ) and SKF-81297 (weanling $n=8$, adult $n=5$ ) are indicated by $\square$ and

$\square$, respectively. Significant differences from vehicle-injected group of the same age are shown: * $p<0.05$, according to post hoc comparisons by Fisher's PLSD test.

pamine continues to develop after weanling and that DARPP-32 plays an important role in this developmental process.

It is well established that injection of a D1R agonist to adult rats can cause an increase in motor activity $(7,11,12)$. This stimulatory locomotor response to D1R agonists has generally been found to be lower in infant (5-10 d old) rats compared with weanling rats $(13,14)$. The difference has varied depending on the dose and preparation of D1R agonist as well as on whether the animals have been habituated to the cage or not. The purpose of our study was to examine whether D1R modulation of motor activity (locomotor and rearing activity) continues to develop after the weanling period. Weanling, which occurs between the third and fourth postnatal weeks in rodents, is a period when organ maturation is accelerated (15). Puberty occurs in mice and rats at approximately the sixth week of life (16). The period between 3 and $6 \mathrm{wk}$ in rodents therefore should correspond roughly to childhood in humans (17). Here we used a low dose of SKF-81297 that would allow detection of subtle behavioral differences. This experimental design allowed us to detect significant differences in response between weanling and adult WT mice. We also found that the locomo-
Weanling

Adult

DARPP-32

$(-/-)$
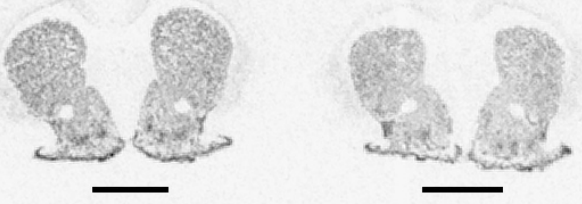

Figure 5. Representative autoradiograms of D1R mRNA expression in male weanling and adult WT and DARPP-32 (-/-) mice. Bar $=2 \mathrm{~mm}$ for weanlings and $3 \mathrm{~mm}$ for adults.

tor stimulatory response seen in adult WT mice is not present in adult DARPP-32 (-/ $)$ mice, whereas the locomotor activity pattern of weanling WT and DARPP-32 (-/-) is very similar. The findings in adult mice are in line with previous findings that DARPP-32 (-/-) mice have a reduced locomotor response to acute injection of cocaine, $10 \mathrm{mg} / \mathrm{kg}$, compared with WT mice (6). Our results suggest that the locomotor stimulatory response to D1R activation is DARPP-32 dependent and that it does not develop until some time between weanling and adult age. Thus, these results suggest that the maturation of the locomotor stimulatory response to D1R activation that occurs after the period of infancy is critically dependent on DARPP-32. This phenomenon cannot be explained by changes in the expression of D1R, because no difference was detected in D1R mRNA expression between weanling and adult WT mice.

The expression of DARPP-32 mRNA has been shown to increase dramatically in all regions of the rat brain during infancy. The adult expression pattern is reached at $\sim 2 \mathrm{wk}$ of age, i.e. in the beginning of the weanling period (18-20). Recently, we reported that SKF-81297 can produce both motor inhibitory and stimulatory effects in nonhabituated adult rats (7). In the present study, we also observed these effects in WT adult mice, albeit less pronounced than those observed in rats. In fact, the inhibitory effects of SKF-81297 were mainly revealed during rearing activity of WT adult mice. It is interesting that the initial inhibitory response on rearing activity that was observed in WT adult mice was also present in adult DARPP-32 (-/-) adult mice. However, the subsequent stimulatory effect was absent in DARPP-32 (-/-) adult mice. In both WT and DARPP-32 (-/-) weanling mice, D1R stimulation resulted in a pronounced decrease in rearing activity. This is in marked contrast to the lack of effects on locomotion activity in both WT and DARPP-32 (-/-) weanling mice. Taken together, these results indicate that the inhibitory response to D1R activation develops earlier than stimulatory response and that it is independent of the DARPP-32 signaling pathway. 
Table 1. Semiquantification of D1 receptor $m R N A$ expression autoradiograms

\begin{tabular}{|c|c|c|c|c|}
\hline & $\begin{array}{c}\text { WT } \\
\text { Weanling }\end{array}$ & $\begin{array}{c}\text { DARPP-32 } \\
(-/-) \\
\text { Weanling }\end{array}$ & $\begin{array}{c}\text { WT } \\
\text { Adult }\end{array}$ & $\begin{array}{c}\text { DARPP-32 } \\
(-/-) \\
\text { Adult }\end{array}$ \\
\hline Caudate putamen & $37371 \pm 596$ & $38997 \pm 811$ & $37557 \pm 575$ & $37448 \pm 437$ \\
\hline Nucleus accumbens & $39748 \pm 602$ & $39096 \pm 354$ & $38933 \pm 411$ & $38522 \pm 559$ \\
\hline Olfactory tuberculum & $48865 \pm 362$ & $48959 \pm 488$ & $47915 \pm 313$ & $47175 \pm 430$ \\
\hline Medial prefrontal cortex & $26116 \pm 96$ & $25753 \pm 198$ & $26315 \pm 124$ & $25869 \pm 267$ \\
\hline
\end{tabular}

Values are given as optical density arbitrary units, means \pm S.E.M., $n=4$ animals/group. For each area the values from two consecutive sections were taken.

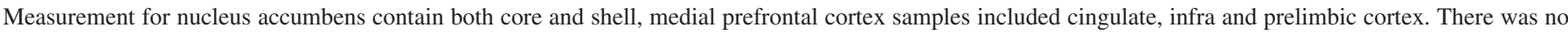
significant difference in any of the areas between WT mice and DARPP-32 (-/-) mice in the two age groups.

Our results underline the overall importance of the D1RDARPP-32 signaling pathway for the regulation of motor activity. DARPP-32 is an important molecule in the D1R signaling pathway, as it will integrate information from a variety of other neurotransmitters and coordinate the regulation of virtually all physiologic responses to dopamine receptor activation $(4,21)$. The maturation process of many of these DARPP-32 converging pathways may occur during different time periods of postnatal development. A likely explanation for our findings, therefore, is that some of the pathways that converge into DARPP-32 continue to develop after weanling. It seems likely that one of the final maturational stages of the dopaminergic system is to obtain a balance in the integration of information that reaches DARPP-32 via a large number of signaling pathways.

\section{REFERENCES}

1. Castellanos FX, Tannock R 2002 Neuroscience of attention-deficit/hyperactivity disorder: the search for endophenotypes. Nat Rev Neurosci 3:617-628

2. Solanto MV 2000 Clinical psychopharmacology of AD/HD: implications for animal models. Neurosci Biobehav Rev 24:27-30

3. Missale C, Nash SR, Robinson SW, Jaber M, Caron MG 1998 Dopamine receptors: from structure to function. Physiol Rev 78:189-225

4. Greengard P, Allen PB, Nairn AC 1999 Beyond the dopamine receptor: the DARPP 32/protein phosphatase-1 cascade. Neuron 23:435-447

5. Greengard P 2001 The neurobiology of dopamine signaling. Biosci Rep 21:247-269

6. Fienberg AA, Hiroi N, Mermelstein PG, Song W, Snyder GL, Nishi A, Cheramy A O'Callaghan JP, Miller DB, Cole DG, Corbett R, Haile CN, Cooper DC, Onn SP, Grace AA, Ouimet CC, White FJ, Hyman SE, Surmeier DJ, Girault J, Nestler EJ, Greengard P 1998 DARPP-32: regulator of the efficacy of dopaminergic neurotransmission. Science 281:838-842
7. Heijtz RD, Beraki S, Scott L, Aperia A, Forssberg H 2002 Sex differences in the motor inhibitory and stimulatory role of dopamine D1 receptors in rats. Eur J Pharmacol 445:97-104

8. Ruskin DN, Rawji SS, Walters JR 1998 Effects of full D1 dopamine receptor agonists on firing rates in the globus pallidus and substantia nigra pars compacta in vivo: test for D1 receptor selectivity and comparison to partial agonist SHF 38393. J Pharmacol Exp Ther 286:272-281

9. Schambra UB, Duncan GE, Breese GR, Fornaretto MG, Caron MG, Fremeau RT Jr 1994 Ontogeny of D1A and D2 dopamine receptor subtypes in rat brain using in situ hybridization and receptor binding. Neuroscience 62:65-85

10. Zelenin S, Aperia A, Diaz Heijtz R 2002 Calcyon in the rat brain: cloning of cDNA and expression of mRNA. J Comp Neurol 446:37-45

11. Abrahams BS, Rutherford JD, Mallet PE, Beninger RJ 1998 Place conditioning with the dopamine D1-like receptor agonist SKF 82958 but not SKF 81297 or SKF 77434. Eur J Pharmacol 343:111-118

12. Cohen C, Perrault G, Sanger DJ 1999 Effects of D1 dopamine receptor agonists on oral ethanol self-administration in rats: comparison with their efficacy to produce grooming and hyperactivity. Psychopharmacology (Berl) 142:102-110

13. Shieh GJ, Walters DE 1996 Stimulating dopamine D1 receptors increases the locomotor activity of developing rats. Eur J Pharmacol 311:103-107

14. Moody CA, Spear LP 1992 Ontogenetic differences in the psychopharmacological responses to separate and combined stimulation of D1 and D2 dopamine receptors during the neonatal to weanling age period. Psychopharmacology (Berl) 106:161-168

15. Henning SJ 1981 Postnatal development: coordination of feeding, digestion, and metabolism. Am J Physiol 241:199-214

16. Spear LP 2000 The adolescent brain and age-related behavioral manifestations Neurosci Biobehav Rev 24:417-463

17. Andersen SL 2003 Trajectories of brain development: point of vulnerability or window of opportunity? Neurosci Biobehav Rev 27:3-18

18. Schalling M, Djurfeldt M, Hokfelt T, Ehrlich M, Kurihara T, Greengard P 1990 Distribution and cellular localization of DARPP-32 mRNA in rat brain. Brain Res Mol Brain Res 7:139-149

19. Gustafson EL, Ehrlich ME, Trivedi P, Greengard P 1992 Developmental regulation of phosphoprotein gene expression in the caudate-putamen of rat: an in situ hybridization study. Neuroscience 51:65-75

20. Ehrlich ME, Rosen NL, Kurihara T, Shalaby IA, Greengard P 1990 DARPP-32 development in the caudate nucleus is independent of afferent input from the substantia nigra. Brain Res Dev Brain Res 54:257-263

21. Centonze D, Picconi B, Gubellini P, Bernardi G, Calabresi P 2001 Dopaminergic control of synaptic plasticity in the dorsal striatum. Eur J Neurosci 13:1071-1077 